\title{
Using K'nex to Teach Large Scale Structures to Architects and Construction Students
}

\section{Dr. Allen C Estes, California Polytechnic State University}

Allen C. Estes is a Professor and Head for the Architectural Engineering Department at California Polytechnic State University in San Luis Obispo. Until January 2007, Dr. Estes was the Director of the Civil Engineering Program at the United States Military Academy (USMA). He is a registered Professional Engineer in Virginia. Al Estes received a B.S. degree from USMA in1978, M.S. degrees in Structural Engineering and in Construction Management from Stanford University in 1987 and a Ph.D. degree in Civil Engineering from the University of Colorado at Boulder in 1997.

\section{Dr. Craig Baltimore, California Polytechnic State University}

Professor in Architectural Engineering at California Polytechnic State University, San Luis Obispo. Licensed California Structural Engineer. Expertise in sustainable knowledge transfer; concentrated solar power for urban areas through heliostat and solar tower power technology; masonry design, technology, and sustainability; and active learning for higher education. Currently his is actively involved with The Masonry Society, Research in Sustainable Grout for Masonry, Elected Official for Local Community Governance, and Teaching Full Time. 


\title{
Using K'nex to Teach Large Scale Structures to Architects and Construction Students
}

\begin{abstract}
The College of Architecture and Environmental Design at California Polytechnic State University in San Luis Obispo (Cal Poly SLO) is the only college in the nation that includes architecture (ARCH), architectural engineering (ARCE) and construction management (CM) programs in the same college. Given the unique mix of disciplines and the emphasis on interdisciplinary collaboration, the ARCH and CM students take a five-course structural engineering sequence from the ARCE department. A challenge of these courses is to maintain some degree of computational rigor while offering a broader perspective that will benefit the ARCH and CM students. This paper reports on one means of accomplishing this using K'nex toys to illustrate the entire design - construction sequence and relate how structure fits into this process during the sequence's culminating course.
\end{abstract}

\section{Introduction}

The College of Architecture and Environmental Design at Cal Poly SLO is the only college in the nation that includes architecture (ARCH), architectural engineering (ARCE) and construction management (CM) programs in the same college. There are numerous opportunities for interdisciplinary collaboration that are not present in other institutions. The college takes advantage of cross-disciplinary learning in the early years of a student's education and with a mandatory upper-division interdisciplinary design experience prior to graduation ${ }^{1,2,3,4}$. The ARCE students take three architecture studios side-by-side with ARCH students taught by ARCH faculty. They also take several courses and studios with CM students taught by the CM faculty as part of their early educational experience. Similarly, the CM and ARCH students take a five course structural engineering sequence taught by the ARCE faculty. The first-two courses in the sequence which cover statics and mechanics of materials of members subjected to axial load and bending are taken side-by-side with ARCE students. The final three courses (structural systems, small scale structures, and large scale structures) are taken only by ARCH and CM students. The comparable versions of these courses taken by the ARCE students require greater theoretical depth and cover more detailed aspects of the governing codes.

Specifically, the final three courses in the sequence taken exclusively by $\mathrm{CM}$ and ARCH students are:

- ARCE 226: Structural Systems which covers the description, behavior and comparison of structural building systems. Topics include structural stability, load flow, framing schemes and building configuration related to vertical and lateral loads. 
- ARCE 315: Small Scale Structures provides an introduction to structures that use timber and steel as the primary construction material. Students are introduced to gravity load carrying systems and lateral load resisting systems using steel and timber elements. The CM and ARCH students analyze structures using free body diagrams and the concept of load flow.

- ARCE 316: Large Scale Structures introduces students to structures that use steel and concrete as the primary construction material focusing on gravity load carrying systems and lateral load resisting systems using steel and concrete elements.

The challenge of the last three courses is to maintain some degree of computational rigor while offering a broader perspective that will benefit the ARCH and CM students. Also, we want to excite these students about structures and integrate structure into their own disciplines in a meaningful way. This paper reports on one means of accomplishing this in ARCE 316 using K'nex toys to illustrate the entire design - construction sequence and relate how structure fits into the process during this final large scale structures course. The project was made possible by a generous $\$ 10,000$ donation of 48,400 K'nex pieces from the K’nex Corporation.

\section{Project Description}

In addition to the lectures, homework and examinations required to attain the ARCE 316 course objectives, a course project was developed to illustrate the entire design/construction process. For the ten-week 2013 winter quarter, the course project requirements were to design and build a 50 foot structure that will support a one-hundred pound concrete panel. The project was to be made entirely of K'nex rods and connectors. Students had to coordinate with university facilities to obtain a building permit, stay within schedule and budget, and document the process by creating a website.

The 32 students in the course are divided into 8 teams:

The Document Team - This team will document the entire process through web site, pictures, and blog. This team is the ONLY team that will not be part of the building teams.

The Facilities Team - This team will work with Cal Poly facilities to assure proper procedures are followed for the construction of a temporary student project.

The Cost Estimating Team (2 teams) - This team will quantify the number and type of pieces needed. There are two teams, and the teams will work independently and confirm each other's estimates.

The Engineering Team (2 teams) - These teams will work together and engineer a design. The structure has to support a 100 pound concrete panel.

The Construction Document Team (2 teams) - These teams work together and create the construction sequence, produce the construction drawings, and coordinate construction and disassembly.

A ten-week quarter does not allow a lot of time. The week-by-week project schedule was as follows: 
Week 1 - Schematic Design. The individual teams participated in a design competition to decide on one single design. The teams engaged in design charettes to develop initial concepts. They developed renderings and posters that communicated their design concepts which they subsequently presented to the class. The class voted on the winning design. Figures 1 and 2 show two of the design alternatives presented, but not selected, by the student teams.

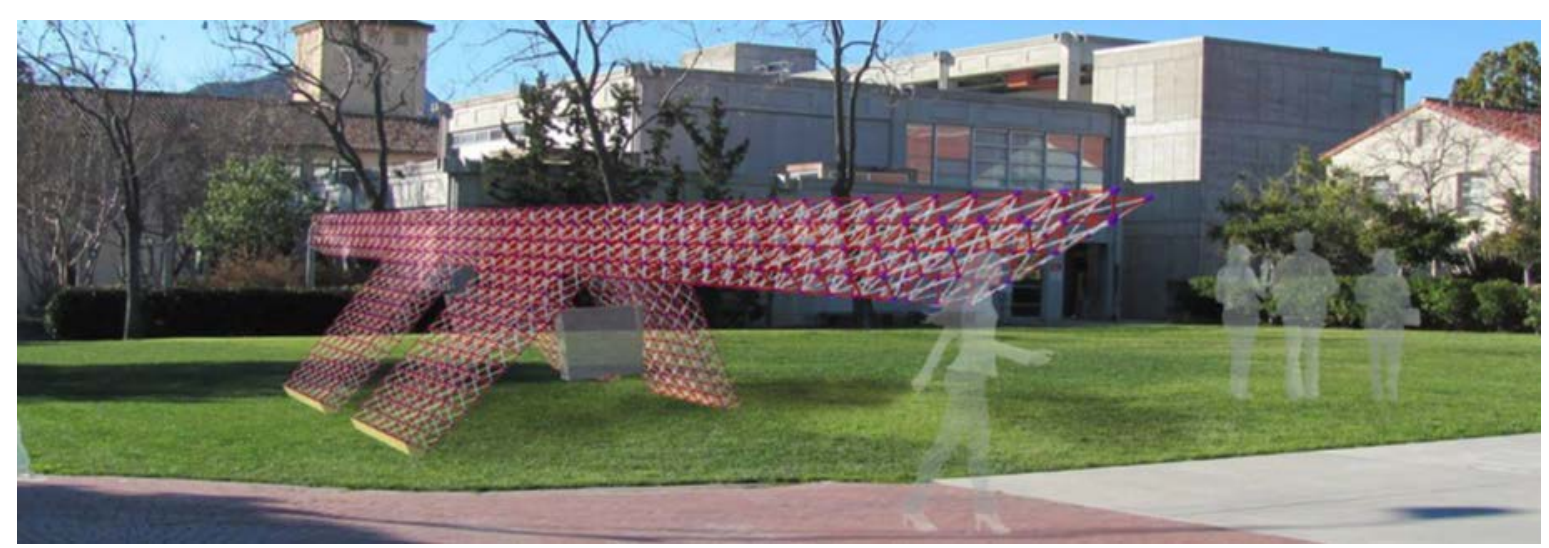

Figure 1. Initial concept for the K'nex structure developed by a student team during the initial design competition

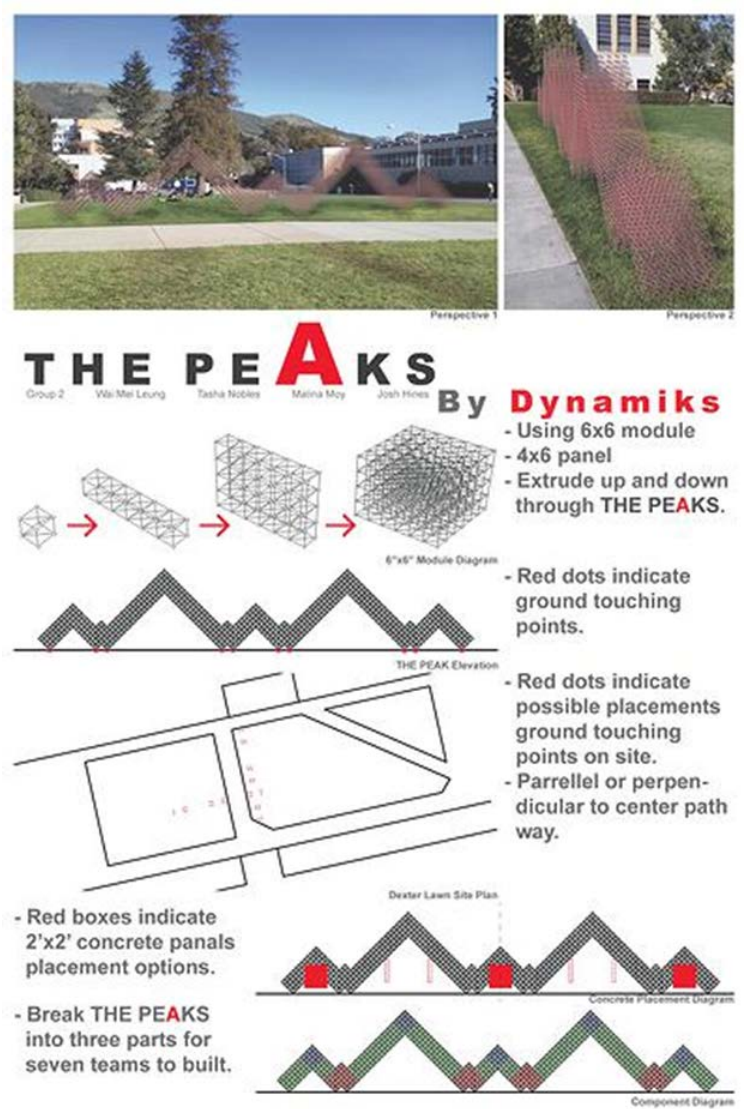

Figure 2. Alternative concept for the large scale K'nex structure developed by a student team in the initial design competition. 
Each student presentation provided general information, a project description, the intent and inspiration for the design, preliminary structural and stability analysis, and a suggested construction sequence. During this process, experienced practitioners from the architecture, construction and engineering professions were invited as guest speakers to share their roles on the design team and offer their perspectives.

Week 2 - Initial Cost Estimate / Begin Engineering. Figures 3 and 4 show a sketch and a model from the final design chosen by the students. The students began doing a static analysis using free body diagrams, load flow, and equilibrium equations to assess how the 100 pound block of concrete would be supported. Figure 5 shows some initial computations that consider both strength and buckling behavior.

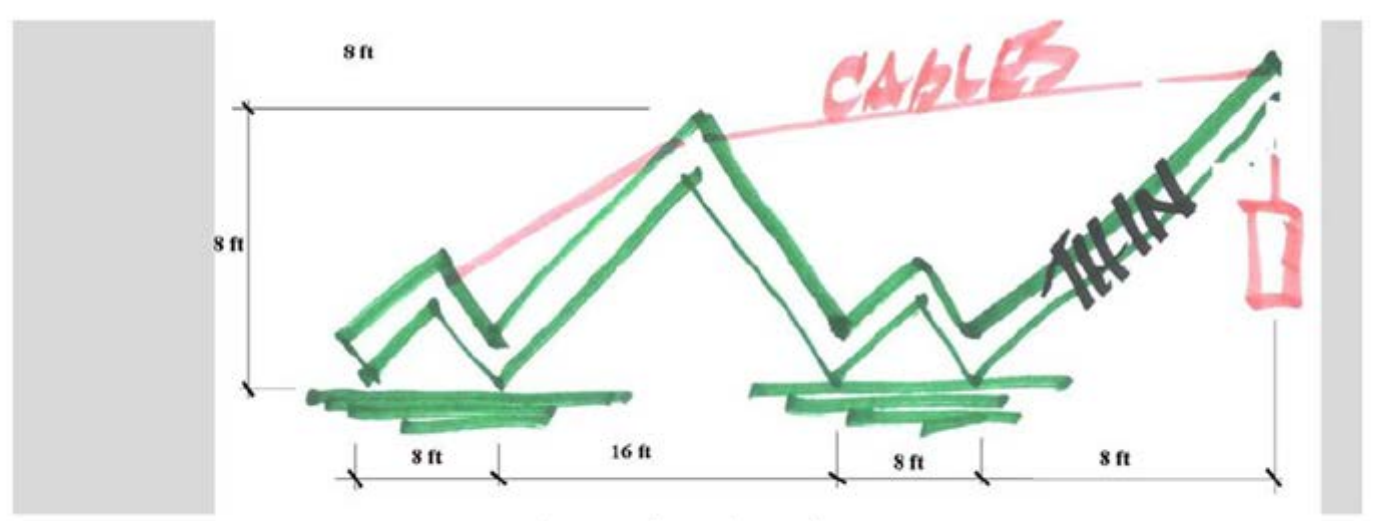

Schematic Elevation

Figure 3: Sketch of the final schematic design for the 50 foot structure.

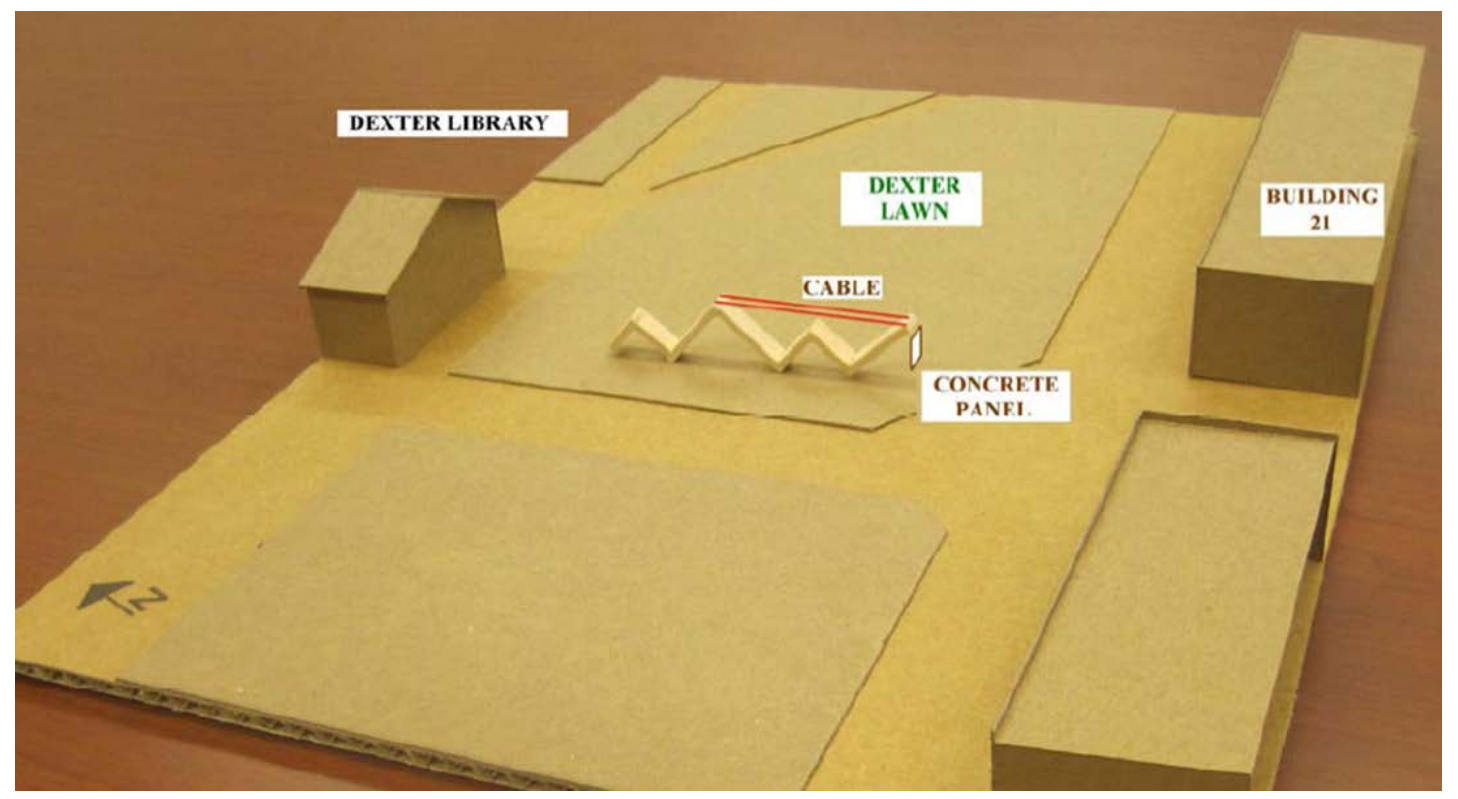

Figure 4: Rough cardboard model showing the scale and proposed position of the structure on Dexter Lawn. 

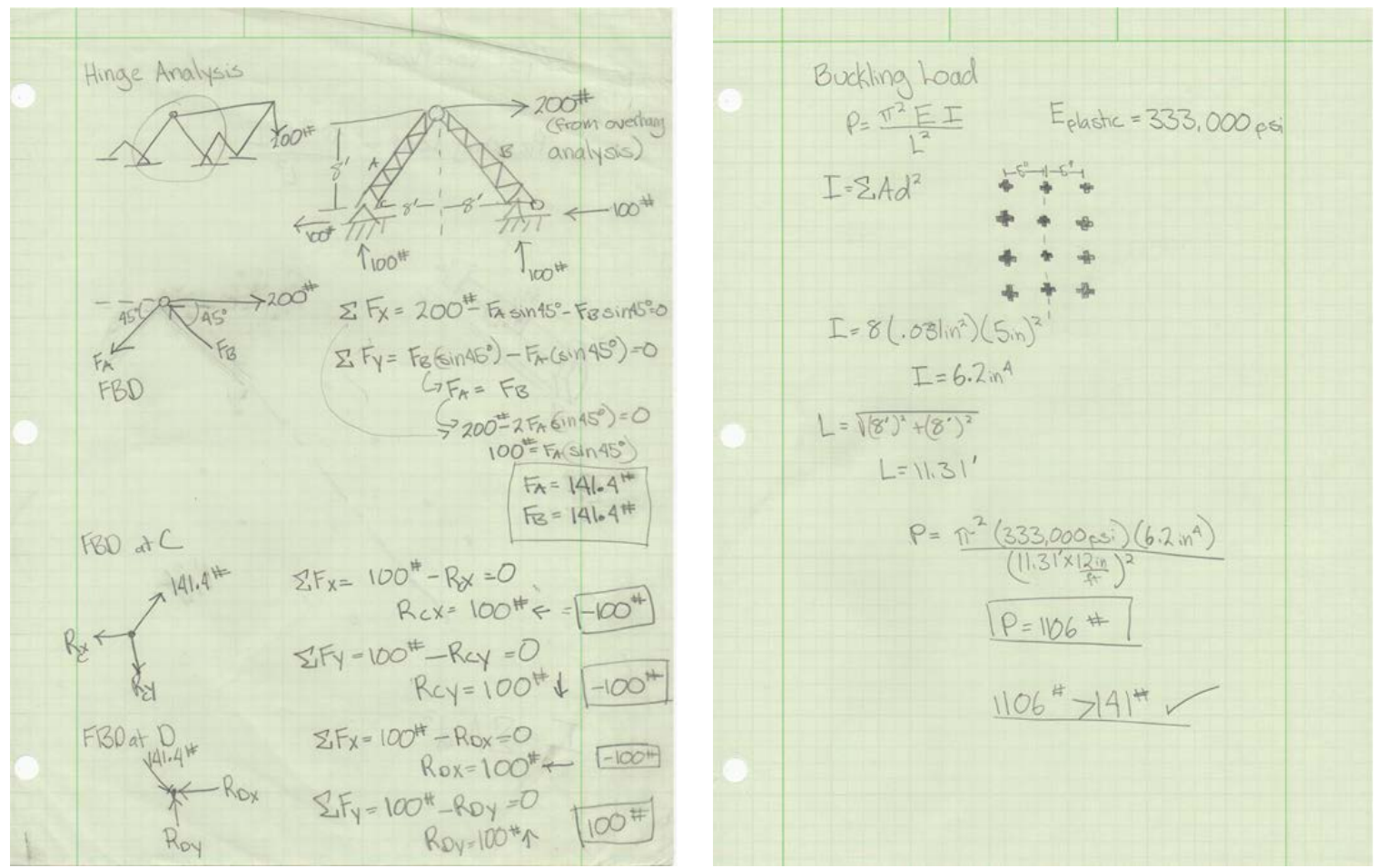

Figure 5. Initial calculations to support the structural design of the 50 foot structure

Week 3 - Engineering. While the course focuses on steel and concrete, the K'nex toys are made of plastic. K'nex pieces consist of various rods and connectors that form 45 degree angles and allow for construction of structures that rely on triangles for their support. They can be analyzed as trusses, but with such large structures bending caused by the self-weight and concrete block weight must also be considered. Because the strength of the K'nex pieces and connections is unknown, the rods and specific connections were tested in the laboratory as shown in Figure 6.
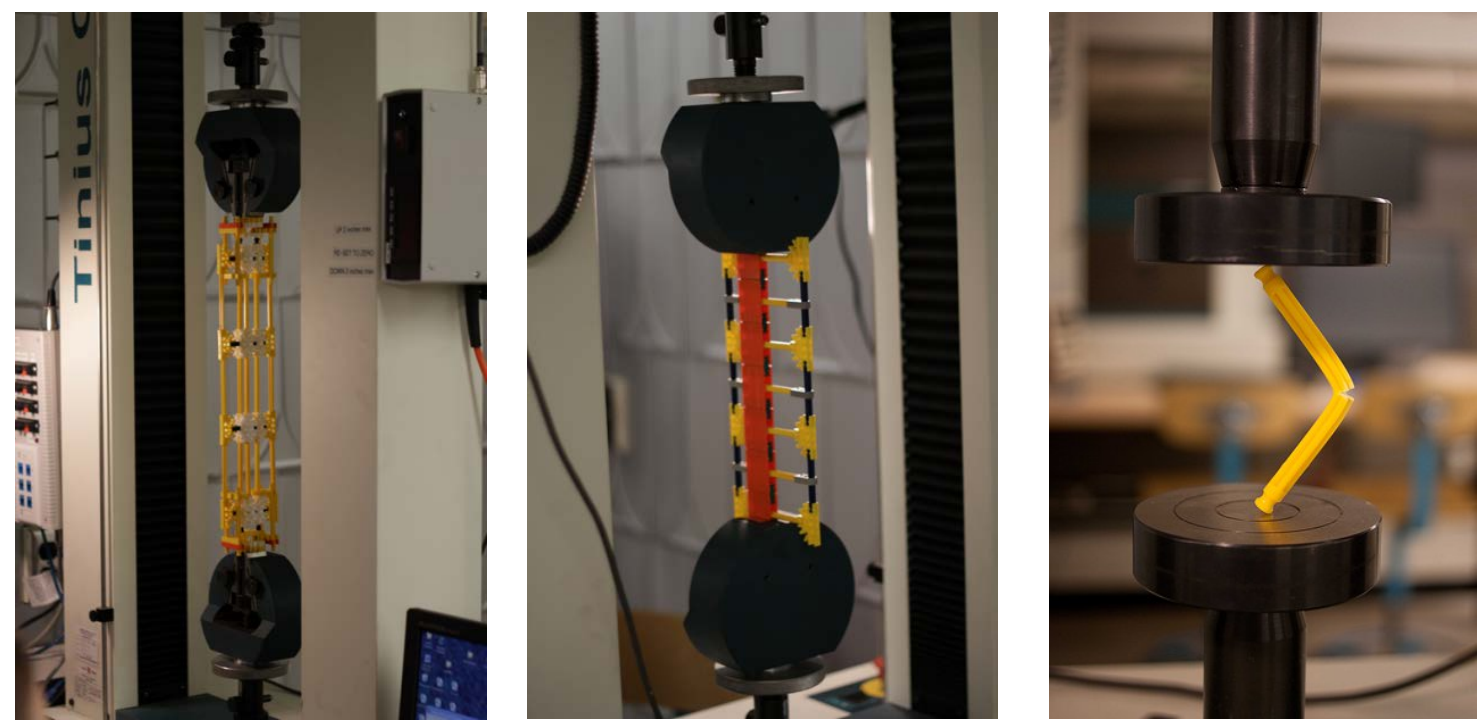

Figure 6. The testing of K’nex rods and specialized connections 
Week 4 - Finalize Engineering. The connection design and structural system was partially developed by trial and error. The students were provided with buckets of K'nex rods and connectors and encouraged to experiment with different configurations (see Figure 7). The connection designs were particularly critical because K'nex toys were not intended to suspend blocks of concrete. The structural system resembled a suspension bridge and the joints in the tension cable needed to carry substantial load. The number of pieces required to complete the design exceeded the number of pieces available, so the size of the structure needed to be reduced from 50 feet to 28 feet. This required a significant design revision which is shown in Figure 8.
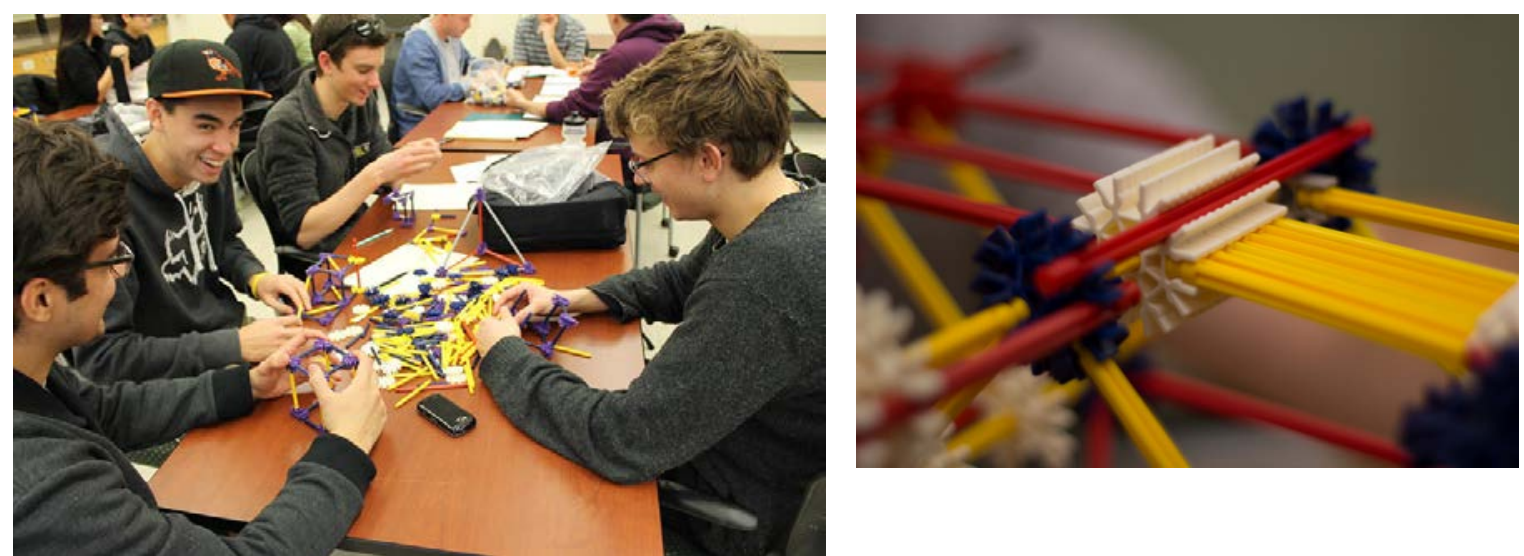

Figure 7. Students experiment with different structural configurations and connection design.
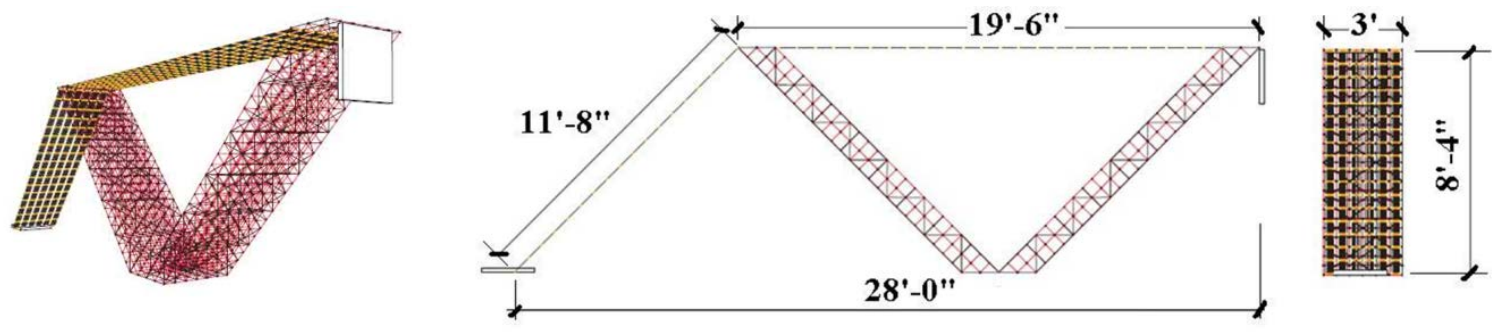

Figure 8. Revised design where the length of the structure and amount of material were reduced. The structural system is modeled on the concept of a suspension bridge.

Week 5 - Design Development and Construction Documents. With the basic design developed, students created bills of materials and more detailed cost estimates based on prices for each K'nex piece and the labor cost of construction. The construction team prepared detailed construction drawings for sub-assemblies and developed the sequence for construction. Figure 9 shows a portion of the cost estimate. 


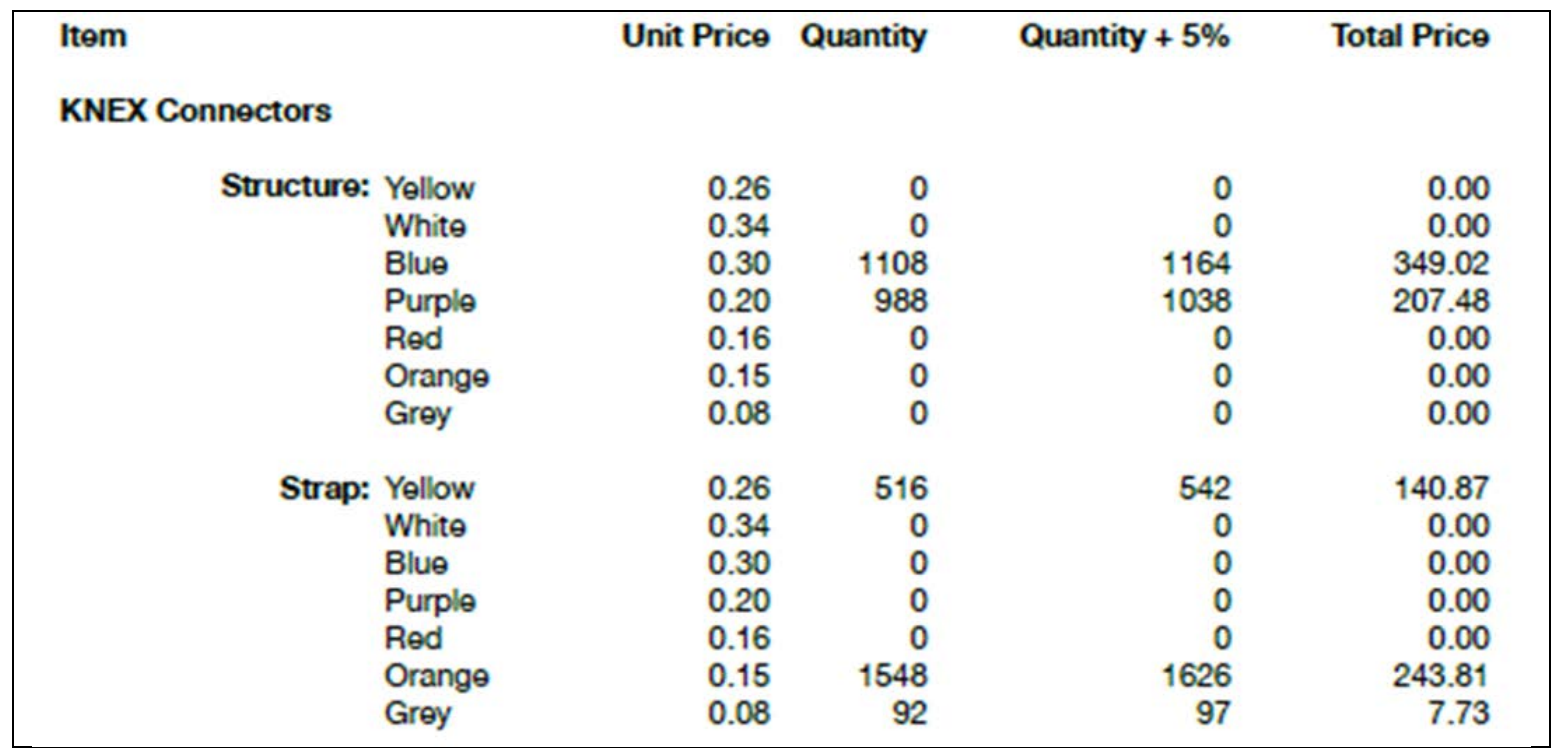

Figure 9: A portion of the materials cost estimate

Week 6 - Construction Documents. The production of the construction drawings and construction sequencing continues. Students start to gather and separate the K'nex pieces need for construction. The building permits for construction are completed by this time.

Weeks 7 and 8 - Final Construction Documents. Construction documents are finalized and construction assignments given to teams. The sub-assemblies were constructed in the high-bay laboratory and tested prior to final construction as shown in Figures 10 and 11. Students had to figure out how to transport the large sub-elements to the job site. The students had on-site engineering challenges as the large elements sagged more than expected and required structural reinforcement.

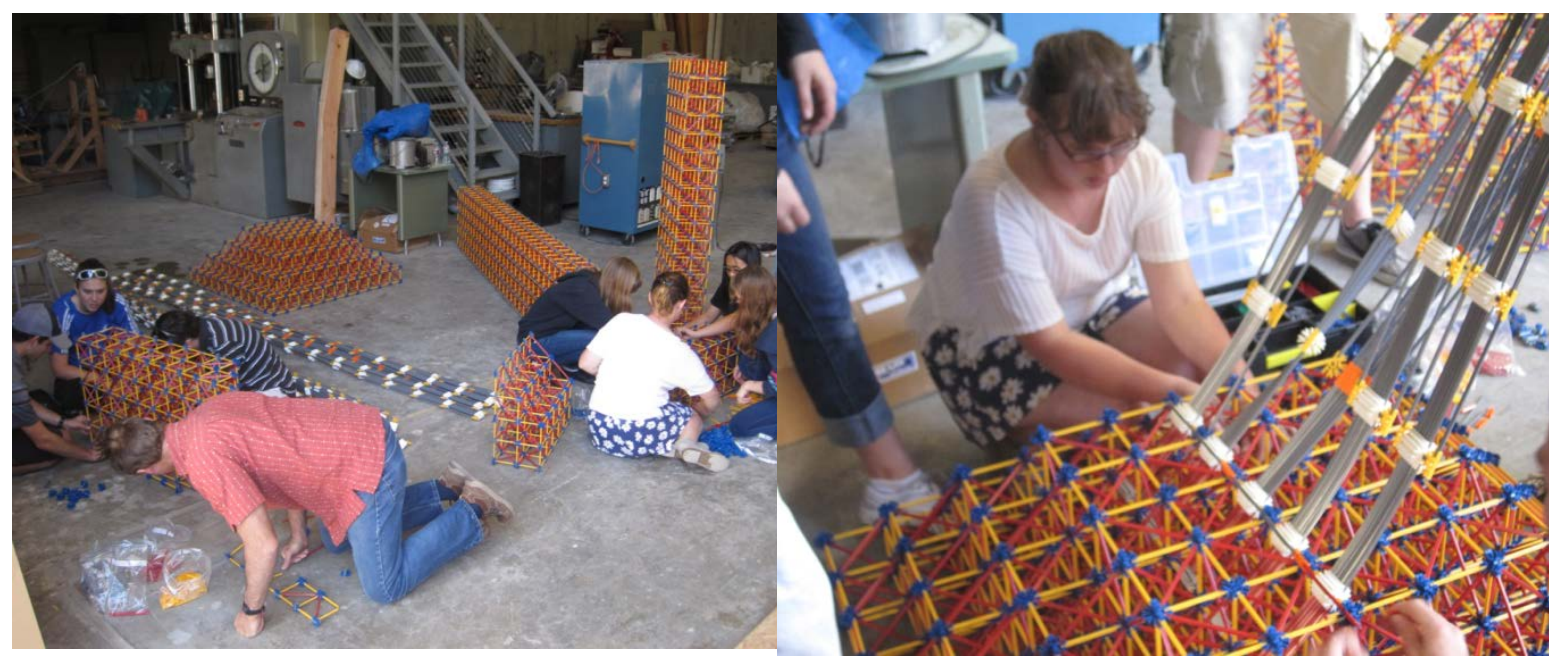

Figure 10. Students constructed and tested the sub-assemblies in the laboratory 


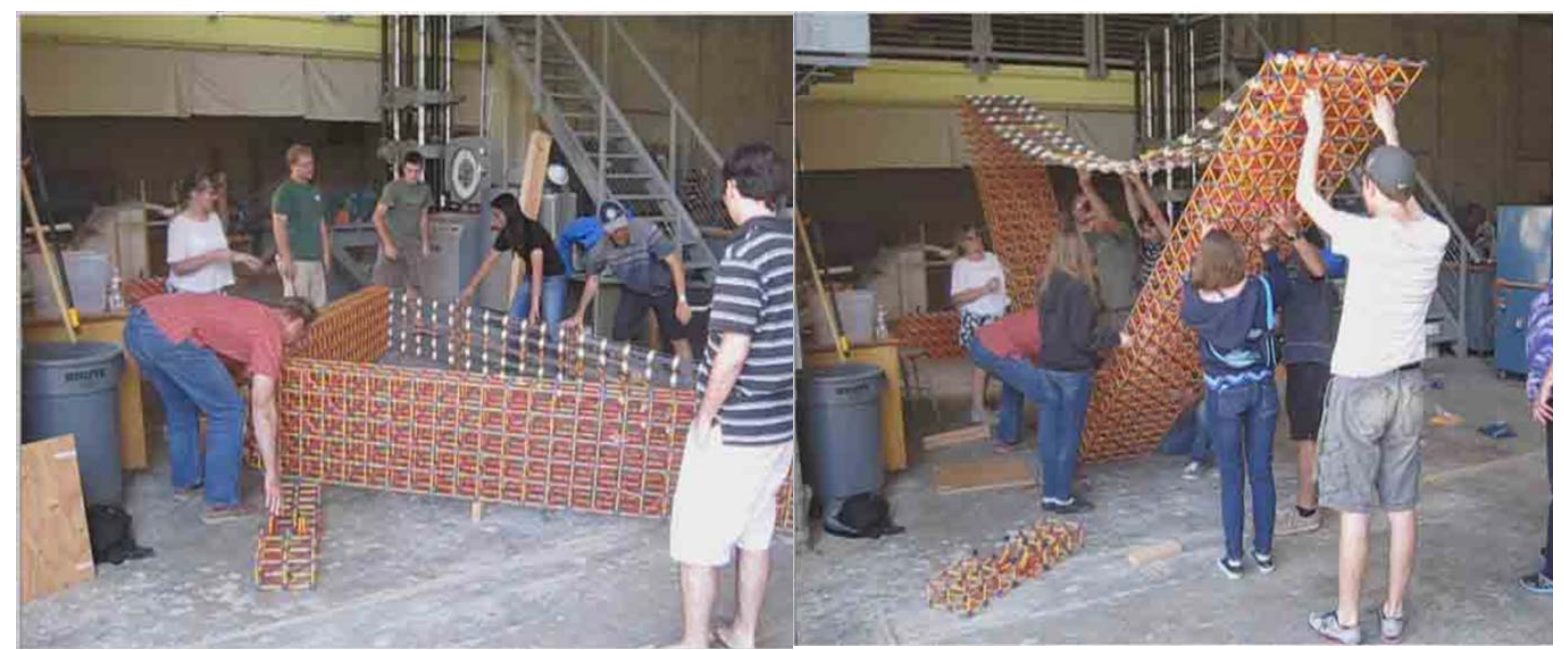

Figure 11: Students encountered new challenges when constructing and erecting the subassemblies.

Week 9 or 10 -- K'NEX Construction, monitoring, disassembly. While the construction rehearsal took approximately eight hours on the weekend, the actual assembly took about an hour and a half. The rehearsal was beneficial for discovering that more pieces were needed, some of the concepts on paper did not work as planned, and pieces did not go together as easily as anticipated. Because a 100 pound block of concrete was being suspended, the students developed a safety plan to protect the public while the structure was displayed.

Figure 12 shows the final structure constructed and on display. The structure was prominently located and generated lots of curiosity and questions. It was reported in the local paper. The structure was dismantled later in the day and the thousands of pieces were returned to their containers.

The feedback from the students on the exercise was overwhelmingly positive. They appreciated being able to link the structural engineering content to the overall design process. Both the ARCH and $\mathrm{CM}$ students appreciated integrating their own disciplines into what might otherwise have been an isolated and disjointed academic experience.

\section{Collaboration with the K'nex Corporation}

This class project obviously required a large number of K'nex rods and connectors to complete this structure. A cost estimate for the 43,000 pieces needed to complete the structure was $\$ 8713$. Buying in bulk would provide a great number of pieces that could be used for other projects. Ultimately the K'nex Corporation donated 48,400 K'nex pieces to the department at a value of $\$ 10,000$. The K'nex Corporation has an Education Division $^{5}$ which focuses heavily on the K-12 market. The ARCE department has long contended that there exists a college-level engineering market for their product. K'nex products have been used extensively in engineering education for constructing structural models, executing design/construction competitions at conferences, illustrating the design-construction process in the classroom, ${ }^{6,7}$ conducting outreach events for K-12 
students, offering engineering exercises at social events, and illustrating theoretical concepts using physical models in the classroom. They are featured prominently in the ASCE Excellence in Civil Engineering Education teaching workshops. The ARCE department intends to continue to use the gift to further the quality of engineering education and share the results with the K'nex Corporation.

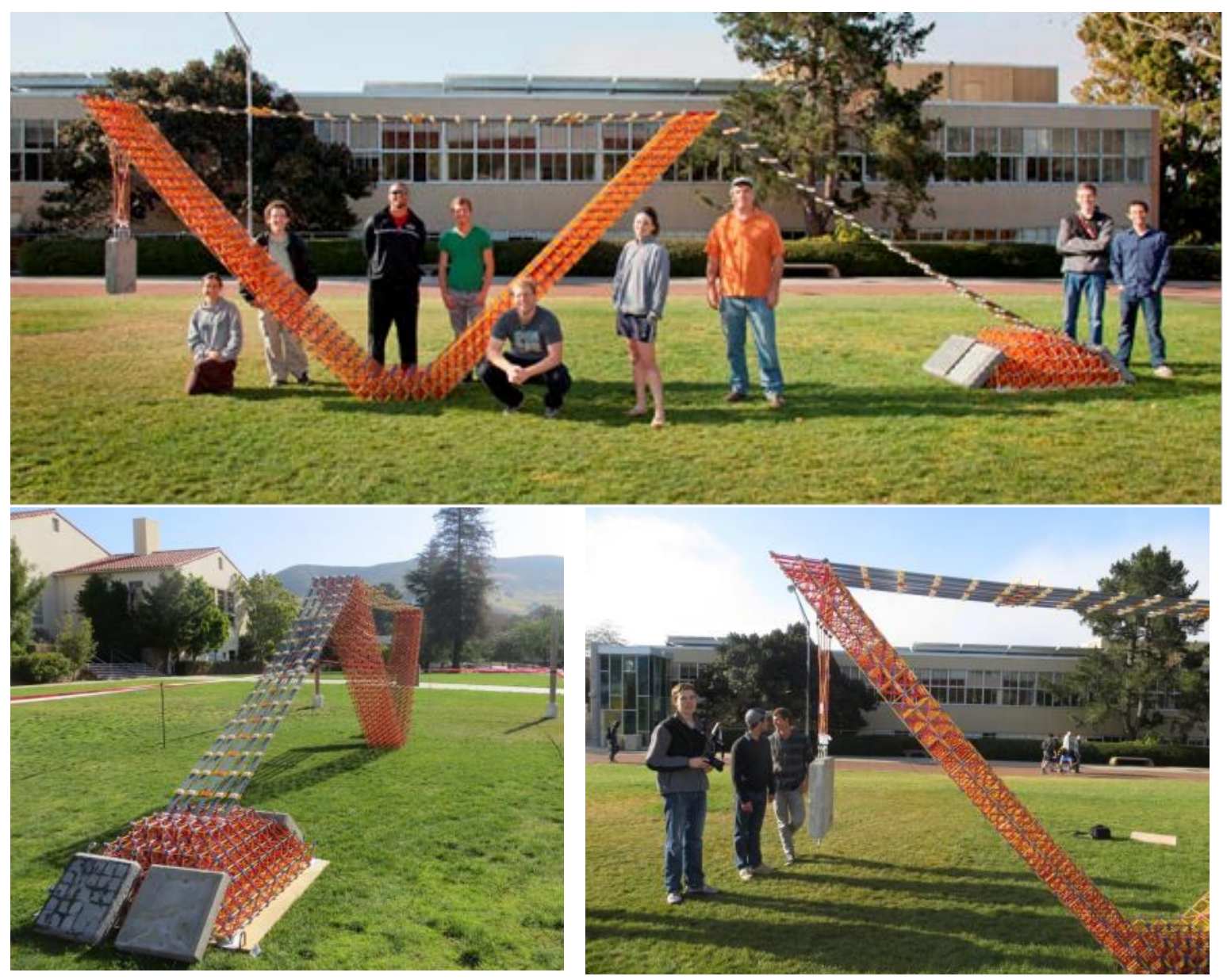

Figure 12: Students display the completed structure on Dexter Lawn

\section{Second Iteration Project}

A second iteration of ARCE 316 using a large-scale structure project was conducted during the summer quarter 2013. The process of using a design competition to decide on a schematic design was implemented again. Student teams engineered the structure, developed the final design, produced construction documents and constructed a large structure using K'nex pieces.....this one in front of the university Performing Arts Center. Rather, than supporting a structural load, these project specifications were more artistic. When a passer-by looks through one tunnel, the statue of the Cal Poly Mustang appears. A second tunnel reveals the top of Bishop Peak, and the third tunnel showed the "P" on the hill in Cal Poly Canyon. Sample construction drawings are shown in Figure 13 and the final structure is shown in Figure 14. The faculty member and students are shown in Figure 15. 


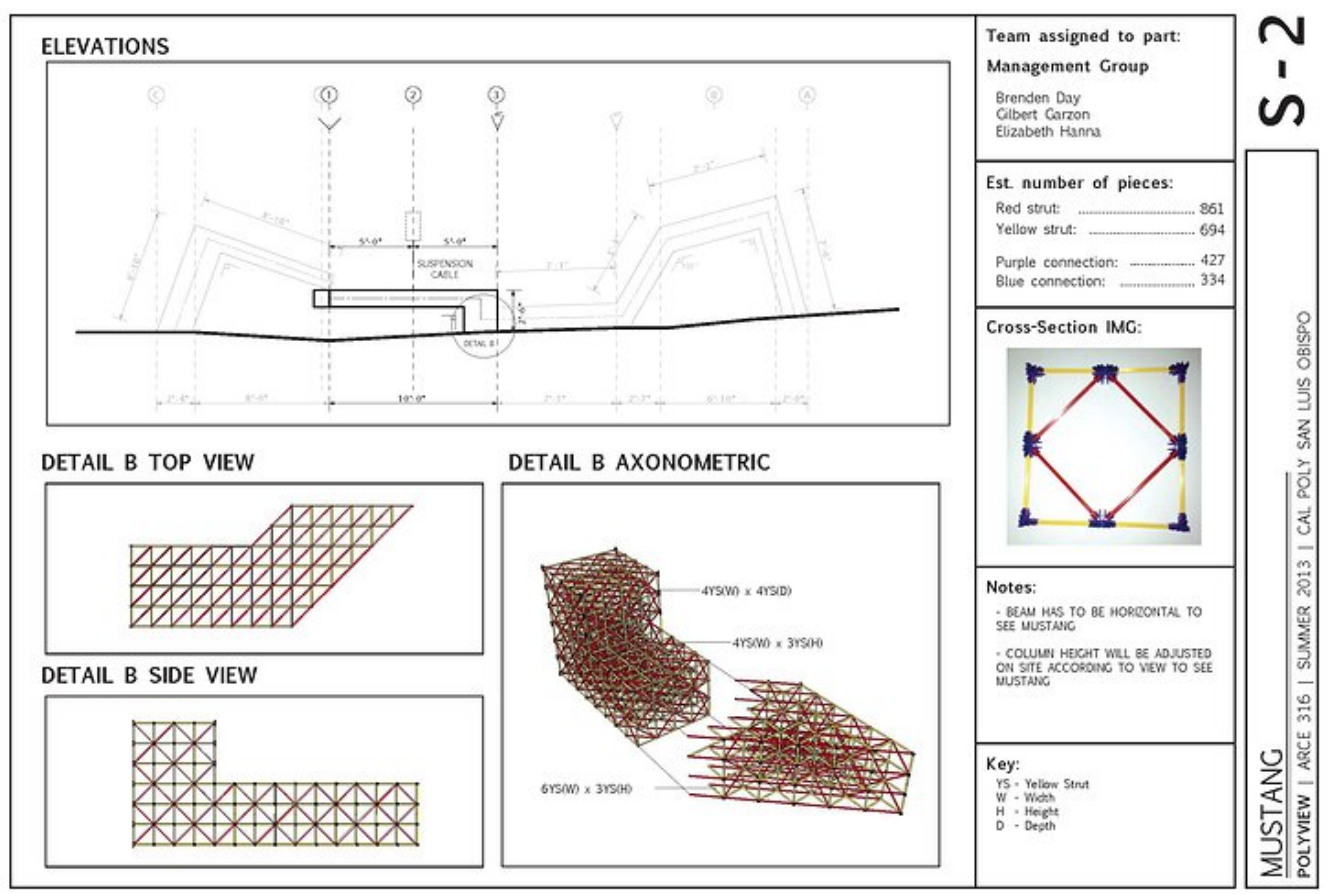

Figure 13: Sample construction drawing from the Summer Quarter 2013 project
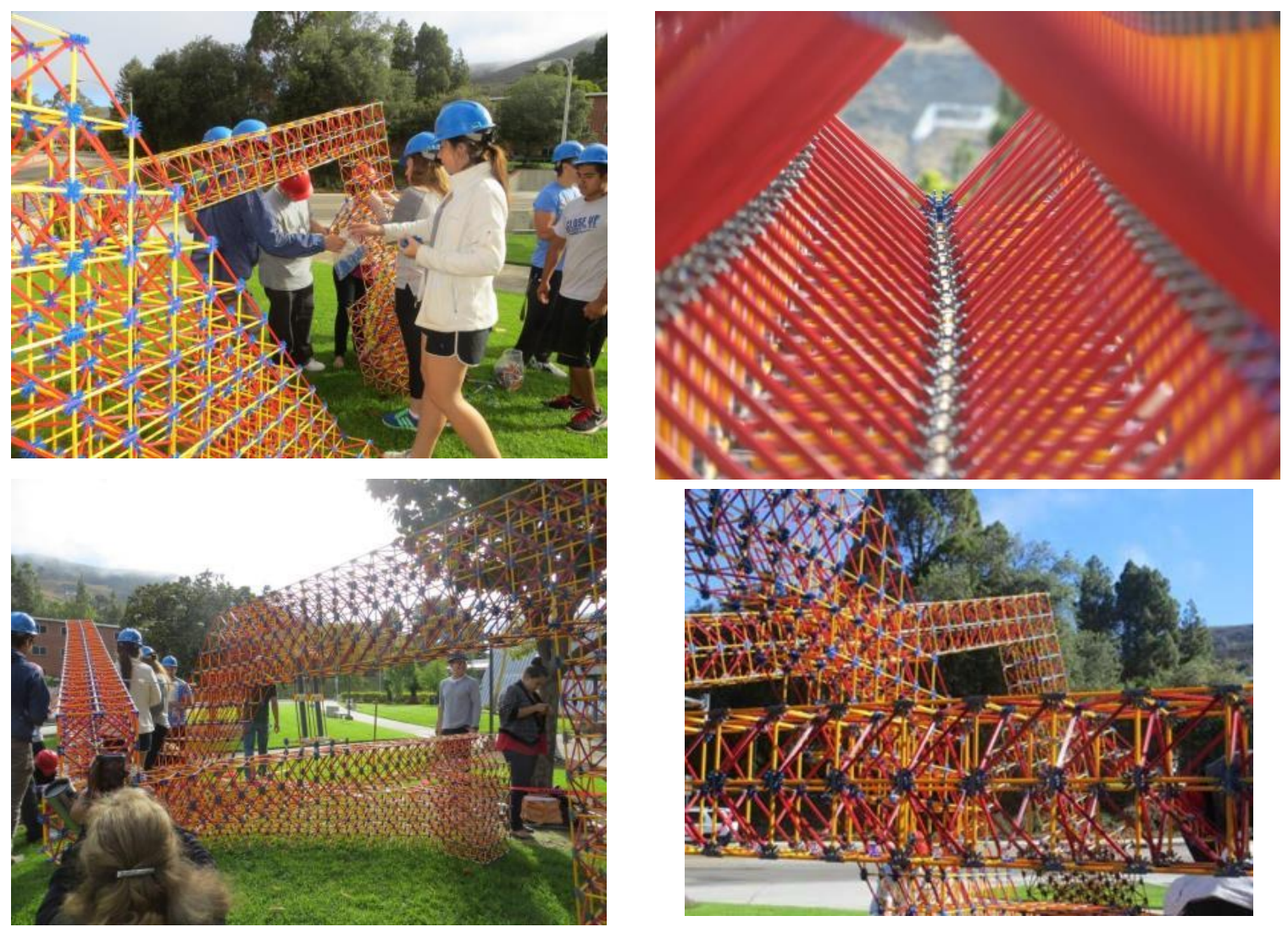

Figure 14: Summer Quarter 2013 ARCE 316 structure on display 


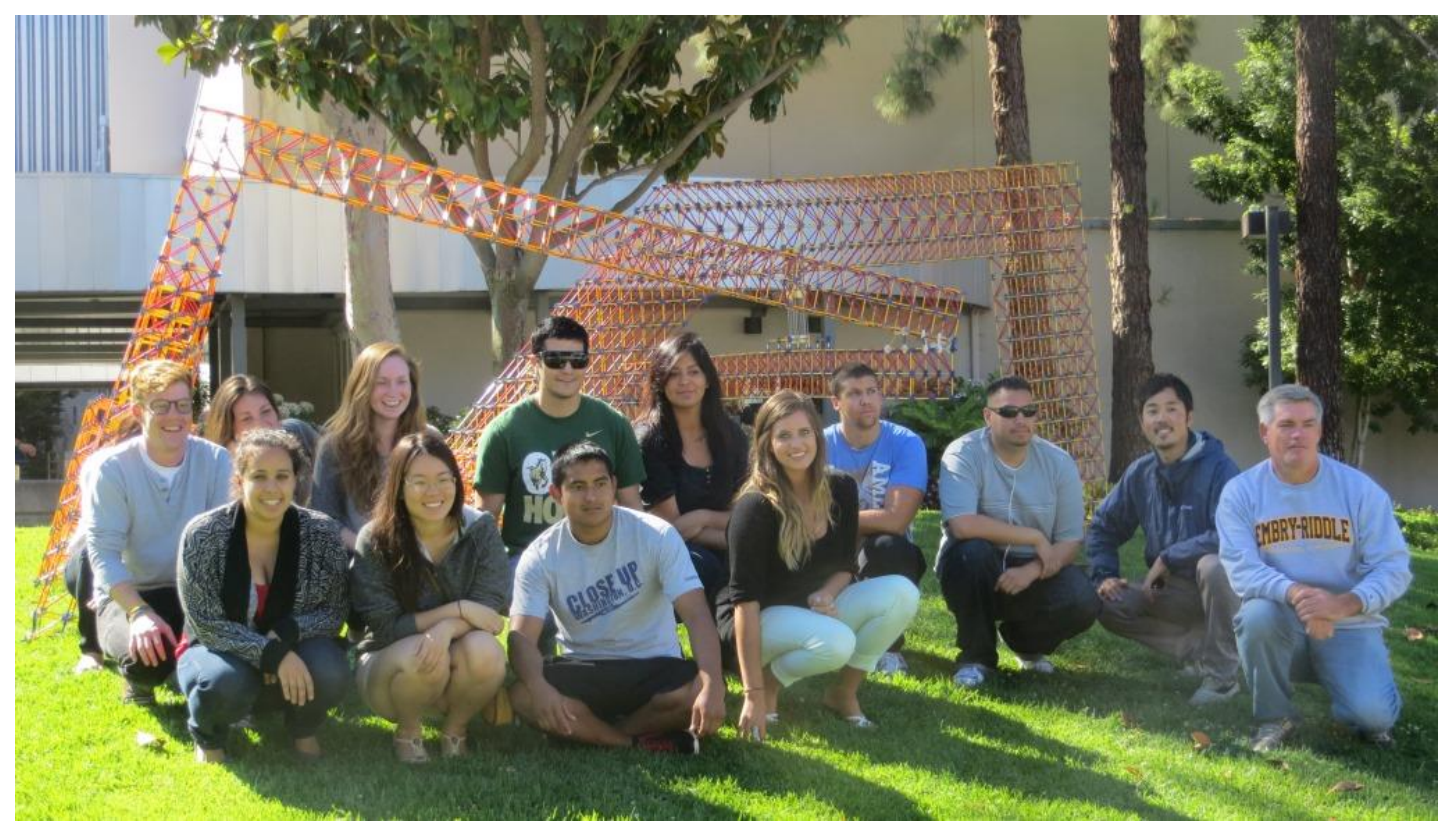

Figure 15. K’nex structure on display in front of the Performing Arts Center

\section{Conclusion}

Teaching structural engineering to ARCH and $\mathrm{CM}$ students can require a somewhat different approach than teaching to ARCE majors. The ARCE majors will be using the latest codes and software to design structural systems that society will rely on for safe performance. The ARCH and CM students do not need the same technical rigor or degree of detail. They often enter the classroom with less natural interest in the topic than engineering students. The ARCH and CM students will hopefully leave their structures sequence with an understanding of the vocabulary and fundamental concepts, an appreciation for structural layout and rough scale of member sizes, and a recognition that structural engineering relates to their own disciplines and there is a compelling reason to know something about it.

The intent of the K'nex large scale structure exercise described in this paper is to provide that perspective. The hands-on voyage through the entire design-construction experience demonstrates the importance of structure and where it fits into the entire process. Student feedback revealed that the project was valuable, relevant and fun. The students ultimately devoted a lot more time to the project than they did to the homework problem sets and found the experience to be more applicable to their own careers.

The K'nex toys are valuable to the engineering classroom and serve a useful and relevant purpose. This program will continue to explore the possibilities and use the K'nex product to enhance and augment classroom instruction. They are colorful and fun and bring a hands-on, physical, tactile element to the classroom. 


\section{Bibliography}

${ }^{1}$ Nelson, J, Nuttall, B and Estes, A. "Interdisciplinary Design - The Good, the Bad and the Ugly” Paper 2010-1004 2010 ASEE Annual Conference and Exposition Proceedings, ASEE, Louisville, June 20-23, 2010.

2 Nuttall, B, Nelson, J and Estes, A. "Interdisciplinary Design - The Saga Continues" ASEE Annual Conference and Exposition Proceedings, ASEE, Vancouver, British Columbia, June 26-29, 2011.

${ }^{3}$ Nuttall, B, Nelson, J and Estes, A. "Interdisciplinary Design - Much Tougher Than It Looks", Civil Engineering Department Heads Annual Conference, Department Head Council Executive Committee, Educational Activities Division, Madison, Wisconsin, May 22-24, 2011.

http://www.asce.org/PPT.Content.aspx?id=1288490721 accessed December 26, 2011.

${ }^{4}$ Estes, A., Nuttall, B., Nelson, J., McDonald, M. and Starzyk, G., "Interdisciplinary Design - Forming and Evaluating Teams” Paper 2013-7404. 2013 ASEE Annual Conference and Exposition Proceedings, ASEE, Atlanta, June 23-26, 2013.

${ }^{5}$ K’nex Corporation. K’nex Eduation, http://www.knex.com/Educators/ accessed January 4, 2014

${ }^{6}$ Ressler, S. “The Project Management K’nexercise: Using Role-Playing to Facilitate Learning About Design and Construction.” 1998 ASEE Annual Conference and Exposition Proceedings, ASEE, 1998.

${ }^{7}$ Estes, A., LaChance, E, and Ressler, S. "K’nexercise: Introducing Students to the Key Participants in the Design-Construction Process.” 2002 ASEE Annual Conference and Exposition Proceedings, ASEE, 2002. 